\title{
Synthesis of the C3-C18 Fragment of Amphidinolides G and H
}

\author{
Andreas F. Petri ${ }^{\dagger}$, John S. Schneekloth Jr. $\ddagger$, Amit K. Mandal ${ }^{\dagger}$, and Craig M. Crews $\mathbf{s}^{\dagger, \ddagger, \S^{\star}}$ \\ $\dagger$ Department of Molecular, Cellular, and Developmental Biology, Yale University, New Haven, Connecticut \\ 06520-8103
}

$\$$ Department of Chemistry, Yale University, New Haven, Connecticut 06520-8103

§Department of Pharmacology, Yale University, New Haven, Connecticut 06520-8103

\begin{abstract}
A synthesis of an amphidinolides $\mathrm{G}$ and $\mathrm{H} \mathrm{C} 3-\mathrm{C} 18$ subunits is reported. The $\mathrm{C} 10-\mathrm{C} 18$ segment 4 was prepared by a Negishi cross-coupling, whereas the synthesis of the $\mathrm{C} 3-\mathrm{C} 9$ fragment 5 employed an asymmetric cyanosilylation as the key step. The two segments were coupled by lithiation of iodide 4 and trapping of the anion with amide 5. The allylic epoxide moiety could be synthesized from the protected anti- mesylate 22 .
\end{abstract}

The amphidinolides are a structurally diverse group of bioactive secondary metabolites isolated from the symbiotic marine dinoflagellate Amphidinium sp. ${ }^{1}$ Amphidinolides G (1) and H (2) are polyketide-based 27- and 26-membered macrolides, respectively, that were first isolated in 1991 by Kobayashi et al. ${ }^{2}$ These two compounds putatively arise from the same seco acid. The gross structures of $\mathbf{1}$ and $\mathbf{2}$ have been elucidated primarily by means of 2D NMR data, whereas the absolute stereochemistry was determined on the basis of X-ray diffraction analysis and degradation ${ }^{3}$ (Figure 1).

Both amphidinolides G (1) and H (2) were shown to be among the most potent cytotoxic amphidinolides. Whereas amphidinolide $\mathrm{H}$ (2) exhibits extremely potent cytotoxic activity against L1210 murine lymphoma and $\mathrm{KB}$ epidermoid carcinoma cells $\left(\mathrm{IC}_{50}=0.00048\right.$ and $0.00052 \mu \mathrm{g} / \mathrm{mL}$, respectively), amphidinolide G (1) showed approximately a 10-fold decrease in activity with $\mathrm{IC}_{50}$ values of 0.0054 and $0.0046 \mu \mathrm{g} / \mathrm{mL}$, respectively. ${ }^{4}$ Amphidinolide $\mathrm{H}$ (2) has been implicated in binding to actin subdomain 4 as a potential mode of action. 5

Because of their remarkable biological activity and challenging structure, amphidinolides $\mathrm{G}$ and $\mathrm{H}$ represent an attractive target for synthetic efforts. Although several syntheses of fragments of amphidinolides $\mathrm{G}$ and $\mathrm{H}$ and the structurally related amphidinolide $\mathrm{B}$ have been published, ${ }^{1,6,7}$ to our knowledge no total synthesis of either of these amphidinolides has been accomplished so far.

Our proposed synthetic route to amphidinolide $\mathrm{H}$ (2) divides the structure into the three major fragments $\mathbf{3}, \mathbf{4}$, and $\mathbf{5}$, allowing a convergent assembly of the molecule (Figure 2). To couple these fragments, we could establish the bond between $\mathrm{C} 9$ and $\mathrm{C} 10$ by nucleophilic addition of an alkyl-lithium species derived from fragment $\mathbf{4}$ into Weinreb amide $\mathbf{5}$. We propose an aldol coupling to construct the $\mathrm{C} 18-\mathrm{C} 19$ bond and a Wittig olefination with commercially available

craig.crews@yale.edu.

Supporting Information Available: Experimental procedures and characterization data for all new compounds. This material is available free of charge via the Internet at http://pubs.acs.org. 
ylide $\mathbf{6}$ across $\mathrm{C} 2$ and C3. Finally, a macrolactonization should complete the carbon skeleton of amphidinolide $\mathrm{G}(\mathbf{1})$ or amphidinolide $\mathrm{H}(\mathbf{2})$.

Our synthetic efforts toward the $\mathrm{C} 10-\mathrm{C} 18$ fragment 4 began with ketone 7 , which was prepared from (-)-pseudoephedrine propionamide under the conditions developed by Myers 8 (Scheme 1). Ketone 7 was further elaborated to propargylic alcohol $\mathbf{8}$ (as a 1:1 mixture of diastereomers) by treatment with ethynylmagnesium bromide. Alcohol $\mathbf{8}$ was then homologated under Crabbé's conditions 9 to form allenol 9 in $68 \%$ yield. Acetylation of 9 was accomplished by treatment with $\mathrm{Ac}_{2} \mathrm{O}$ and DMAP in pyridine at $45^{\circ} \mathrm{C}$ to provide allenic acetate 10 in $76 \%$ yield.

Having established a synthetic route to access the allenic acetate 10, we turned our attention to the synthesis of the 1,3-diene moiety. Our laboratory has previously demonstrated that the (E)-1,3-diene moiety of amphidinolide B can be synthesized from an allenic acetate precursor. $7 \mathrm{f}, 10$ When the allenic acetate $\mathbf{1 0}$ was treated under the reaction conditions previously described by Bäckvall ${ }^{11}\left(\mathrm{LiI}, \mathrm{Pd}(\mathrm{OAc})_{2}, \mathrm{AcOH}, 40^{\circ} \mathrm{C}\right)$, the iodide-mediated $\mathrm{S}_{\mathrm{N}} 2^{\prime}$ reaction gave the vinyl iodide $\mathbf{1 1}$ in $80 \%$ yield and a low $E / Z$-selectivity of 2:1. We were pleased to find that the iodide 11 could be obtained in 76\% yield and an E/Z-ratio of 10:1 by performing the reaction in the absence of Pd catalyst at room temperature (Scheme 2). Moving forward, we next concentrated our efforts to establish the $\mathrm{C} 12-\mathrm{C} 13$ bond by reacting vinyl iodide $\mathbf{1 1}$ with a suitable coupling partner. Gratifyingly, iodide $\mathbf{1 1}$ could be reacted with the commercially available organozinc species 12 under Negishi-type cross-coupling conditions ${ }^{12}$ to give the ester 13 in $92 \%$ yield. No isomerization of the diene moiety was observed under these reaction conditions. Ester 13 could then be converted into alcohol 14 by reduction with DIBALH (92\%). It was determined that alcohol $\mathbf{1 4}$ decomposes to an uncharacterized mixture of side products upon exposure to silica gel or even neutralized silica gel. Therefore, the crude alcohol 14 was carried forward without further purification. Functionalization of alcohol $\mathbf{1 4}$ to the iodide 4 proved to be nontrivial. All attempts to convert alcohol $\mathbf{1 4}$ directly to iodide $\mathbf{4}$ left the starting material unchanged or resulted in decomposition of the substrate. ${ }^{13}$ Therefore, alcohol 14 was brominated $\left(\mathrm{CBr}_{4}, \mathrm{PPh}_{3}, 2\right.$,6-lutidine, $\left.99 \%\right)$ and a subsequent Finkelstein reaction (NaI, acetone, $\Delta$ ) introduced the iodine in excellent yield (92\%) and furnished the $\mathrm{C} 10-\mathrm{C} 18$ fragment 4. Alkyl iodide 4 could be stored at $-20^{\circ} \mathrm{C}$ for 3 months without any noticeable decomposition.

We proposed to synthesize the $\mathrm{C} 3-\mathrm{C} 9$ fragment 5 via an asymmetric cyanosilylation of known aldehyde $\mathbf{1 5}^{14}$ as key step. In our initial attemps, we investigated the cyanosilylation method developed by Uang ${ }^{15}$ (which left the aldehyde 15 unchanged) and the method of $\mathrm{Pu},{ }^{16}$ which gave the protected cyanohydrin $\mathbf{1 7}$ in $30 \%$ yield and $69 \%$ ee. We were pleased to find that we could access the TMS-protected cyano-hydrin 17 in $75 \%$ chemical yield and $80 \%$ ee $^{17}$ by employing the chiral ligand (+)-16 and $\mathrm{Ti}(\mathrm{O} i \mathrm{Pr})_{4}$ as described by Feng and co-workers ${ }^{18}$ (Scheme 3). Exposure of $\mathbf{1 7}$ to $\mathrm{HCl}$ in ethanol produced the $\alpha$-hydroxyester $\mathbf{1 8}$ in $89 \%$ yield. At this stage, the stereochemistry of the $\mathrm{C} 8-\mathrm{OH}$ group was assigned by using the modified Mosher method, ${ }^{19}$ which revealed the $(S)$-configuration of $\alpha$-hydroxyester 18. Amidation of ester 18 using the Merck procedure ${ }^{20}((\mathrm{MeO}) \mathrm{MeNH} \cdot \mathrm{HCl}, i \mathrm{PrMgCl})$ afforded Weinreb amide 19 in $84 \%$ yield.

The choice of protecting group for the hydroxy function at $\mathrm{C} 8$ was crucial. As it was necessary to utilize a chelating protecting group, initial studies with a PMB ether or a MOM ether were carried out (not shown). Unfortunately, later substrates containing the 1,3-diene unit of amphidinolides $\mathrm{G}$ and $\mathrm{H}$ were prone to decomposition upon treatment with DDQ or under acidic conditions, presumably by way of isomerization. In order to circumvent this issue, we chose to protect the C8 hydroxy function of $\mathbf{1 9}$ as an MTM (methylthiomethyl) ether ${ }^{21}$ (DMSO, $\mathrm{AcOH}, \mathrm{Ac}_{2} \mathrm{O}, 60 \%$ ), thus completing the synthesis of the $\mathrm{C} 3-\mathrm{C} 9$ fragment 5. 
With both fragments $\mathbf{4}$ and $\mathbf{5}$ securely in hand, we envisioned a nucleophilic addition into a Weinreb amide as the key coupling step to combine the two fragments. The lithium-halogen exchange to convert the alkyl iodide 4 to the alkyllithium species 20 proved to be a challenging transformation. In our initial experiments, we performed the lithium-halogen exchange of iodide $\mathbf{4}$ using the standard protocol, ${ }^{22}$ which involves treatment of $\mathbf{4}$ with 2.2 equiv of $t \mathrm{BuLi}$ at $-78{ }^{\circ} \mathrm{C}$ and subsequent stirring at room temperature for $1 \mathrm{~h}$ to decompose excess $t$-BuLi. Under these conditions, the lithiation was found to be lacking reproducibility, and the yield of alkyllithium species $\mathbf{2 0}$ was usually $<40 \%{ }^{23}$ The low yields of $\mathbf{2 0}$ could potentially be caused by an intramolecular cyclization of the alkyllithium moiety into the 1,3-diene system, as such cyclizations are known to occur at room temperature. ${ }^{24}$ Since the cyclization of unsaturated organolithiums can be suppressed at low temperatures, we were able to circumvent this problem by modifying the lithiation protocol. ${ }^{25}$ When we treated iodide $\mathbf{4}$ with 1.8 equiv of $t$-BuLi at $-78^{\circ} \mathrm{C}$ and stirred the reaction for $10 \mathrm{~min}$ at $-40{ }^{\circ} \mathrm{C}$, lithium halogen exchange to 20 occurred smoothly and subsequent coupling with Weinreb amide 5 at $-78{ }^{\circ} \mathrm{C}$ yielded the ketone 21 in $72 \%$ yield $^{26}$ (Scheme 4). The chelation-controlled reduction of ketone $21\left(\mathrm{LiI}_{/} \mathrm{LiAlH}_{4}, \mathrm{Et}_{2} \mathrm{O}\right.$, anti:syn 8:1) provided the anti alcohol in 87\% yield as a single diastereomer after flash chromatography. ${ }^{27}$ Mesylation of the secondary alcohol $\left(\mathrm{MsCl}, \mathrm{Et}_{3} \mathrm{~N}\right.$, rt) afforded $\mathbf{2 2}$ in $91 \%$ yield. MTM deprotection was accomplished under mild alkylating conditions (MeI,

$\mathrm{NaHCO}_{3}$, aqueous acetone, 68\%), and subsequent treatment of the hydroxy mesylate with LiHMDS afforded the allylic epoxide $\mathbf{2 3}$ in $80 \%$ yield. Epoxide $\mathbf{2 3}$ corresponds to the fully functionalized C3-C18 fragment of amphidinolides G (1) and H (2).

In summary, we have described an efficient synthetic route to the C3-C18 subunit $\mathbf{2 3}$ of amphidinolides $\mathrm{G}$ and $\mathrm{H}$. Our studies demonstrate that the 1,3-diene moiety of these natural products can be assembled by an $\mathrm{S}_{\mathrm{N}} 2^{\prime}$ reaction of an allenic acetate 10. We have also demonstrated that a Negishi-type cross-coupling between a vinyl iodide $\mathbf{1 1}$ and an alkylzinc species 12 can be employed to assemble the C12-C13 bond. The two advanced fragments 4 and $\mathbf{5}$ could be combined to ketone $\mathbf{2 1}$ by a lithiation/nucleophilic addition sequence.

Furthermore, we have shown that the allylic epoxide moiety of amphidinolides $\mathrm{G}(\mathbf{1})$ and $\mathrm{H}$ (2) can be effectively synthesized from the protected anti mesylate 22. With the effective assembly of the 1,3-diene moiety and the allylic epoxide, two important characteristic structural features of amphidinolides $\mathrm{G}$ and $\mathrm{H}$ have been synthesized successfully. Efforts toward the eventual total synthesis of $\mathbf{2}$ are currently being pursued in our laboratory.

\section{Acknowledgment}

We gratefully acknowledge financial support from the NIH (GM062120). A.F.P. thanks the Deutsche Forschungsgemeinschaft for a postdoctoral fellowship. J.S.S. thanks the American Chemical Society, Division of Medicinal Chemistry, and Aventis Pharmaceuticals for a predoctoral fellowship.

\section{References}

1. For reviews, see:(a) Kobayashi J, Ishibashi M. Chem. Rev 1993;93:1753. (b) Chakraborty T, Das S. Curr. Med. Chem.: Anti-Cancer Agents 2001;1:131. (c) Kobayashi J, Shimbo K, Kubota T, Tsuda M. Pure Appl. Chem 2003;75:337. (d) Kobayashi J, Tsuda M. Nat. Prod. Rep 2004;21:77. [PubMed: 15039836] (e) Kobayashi J, Kubota T. J. Nat. Prod 2007;70:451. [PubMed: 17335244]

2. Kobayashi J, Shigemori H, Ishibashi M, Yamasu T, Hirota H, Sasaki T. J. Org. Chem 1991;56:5221.

3. Kobayashi J, Shimbo K, Sato M, Shiro M, Tsuda M. Org. Lett 2000;2:2805. [PubMed: 10964370]

4. Kobayashi J, Shimbo K, Sato M, Tsuda M. J. Org. Chem 2002;67:6585. [PubMed: 12227785]

5. (a) Usui T, Kazami S, Dohmae N, Mashimo Y, Kondo H, Tsuda M, Terasaki AG, Ohashi K, Kobayashi J, Osada H. Chem. Biol 2004;11:1269. [PubMed: 15380187] (b) Saito S-Y, Feng J, Kira A, Kobayashi J, Ohizumi Y. Biochem. Biophys. Res. Commun 2004;320:961. [PubMed: 15240142]

6. Amphidinolide H:(a) Chakraborty TK, Suresh VR. Tetrahedron Lett 1998;39:7775. (b) Chakraborty TK, Suresh VR. Tetrahedron Lett 1998;39:9109. (c) Liesener FP, Kalesse M. Synlett 2005:2236. (d) 
Liesener FP, Jannsen U, Kalesse M. Synthesis 2006:2590. (e) Formentín P, Murga J, Carda M, Marco JA. Tetrahedron: Asymmetry 2006;17:2938. (f) Deng L, Ma Z, Zhang Y, Zhao G. Synlett 2007:87.

7. For representative papers regarding synthetic work on amphidinolide B, see(a) Chakraborty TK, Suresh VS. Chem. Lett 1997;6:565. (b) Eng HM, Myles DC. Tetrahedron Lett 1999;40:2275. (c) Ishiyama H, Takemura T, Tsuda M, Kobayashi J. Tetrahedron 1999;55:4583. (d) Cid MB, Pattenden G. Tetrahedron Lett 2000;41:7373. (e) Zhang W, Carter RG. Org. Lett 2005;7:4209. [PubMed: 16146389] (f) Mandal AK, Schneekloth JS Jr, Crews CM. Org. Lett 2005;7:3645. [PubMed: 16092840] (g) Mandal AK, Schneekloth JS Jr, Kuramochi K, Crews CM. Org. Lett 2006;8:427. [PubMed: 16435851] (h) Gopalarathnam A, Nelson SG. Org. Lett 2006;8:7. [PubMed: 16381554]

8. (a) Myers AG, McKinstry L. J. Org. Chem 1996;61:2428. (b) Myers AG, Yang BH, Chen H, McKinstry L, Kopecky DJ, Gleason JL. J. Am. Chem. Soc 1997;119:6496.

9. Searles S, Li Y, Nassim B, Lopes M-TR, Tran PT, Crabbé P. J. Chem. Soc., Perkin Trans 1984;1:747. 10. Schneekloth JS Jr, Pucheault M, Crews CM. Eur. J. Org. Chem 2007:40.

11. Horváth A, Bäckvall J-E. J. Org. Chem 2001;66:8120. [PubMed: 11722214]

12. For a recent review on Negishi-type couplings, see:Negishi E, Hu Q, Huang Z, Qian M, Wang G. Aldrichimica Acta 2005;38:71.

13. Other conditions explored were PPh3/I2/imidazole; PPh3/CI4; NaI/heat; and MsCl/NaI.

14. Marshall JA, Jiang H. J. Org. Chem 1999;64:971. [PubMed: 11674171]

15. Uang BJ, Fu IP, Hwang CD, Chang CW, Yang CT, Hwang DR. Tetrahedron 2004;60:10479.

16. Qin YC, Liu L, Pu L. Org. Lett 2005;7:2381. [PubMed: 15932203]

17. The enantiomeric excess of this reaction was determined by Mosher ester analysis of the Rhydroxyester 18.

18. Li Y, He B, Qin B, Feng X, Zhang G. J. Org. Chem 2004;69:7910. [PubMed: 15527269]

19. (a) Dale JA, Mosher HS. J. Am. Chem. Soc 1973;95:512. (b) Ohtani I, Kusumi T, Kashman Y, Kakisawa H. J. Am. Chem. Soc 1991;113:4092.

20. Williams JM, Jobson RB, Yasuda N, Marchesini G, Dolling U-H, Grabowski EJJ. Tetrahedron Lett 1995;36:5461.

21. Pojer PM, Angyal SJ. Aust. J. Chem 1978;31:1031.

22. Bailey WF, Punzalan ER. J. Org. Chem 1990;55:5404.

23. The yield of alkyllithium species $\mathbf{2 0}$ was determined by trapping $\mathbf{2 0}$ with amide $\mathbf{5}$ and isolation of the ketone $\mathbf{2 1}$ thus formed.

24. For reviews about the cyclization of usaturated organolithiums, see:(a)ClaydenJOrganolithiums: SelectiVity for Synthesis2002Vol. 3New YorkPergamon Press: New York293335 (b) Mealy MJ, Bailey WF. J. Organomet. Chem 2002;646:59.

25. Bailey WF, Jiang X. Tetrahedron 2005;61:3183.

26. Because the amide $\mathbf{5}$ had an ee of $80 \%$, the coupling yielded $\sim 10 \%$ of the ( $8 R$ )-epimer of ketone $\mathbf{2 1}$, which could be separated by column chromatography at this stage.

27. The relative stereochemistry was confirmed after converting the alcohol into an acetonide by NOESY NMR spectroscopy (see Supporting Information).

Org Lett. Author manuscript; available in PMC 2008 November 17. 
amphidinolide G (1):

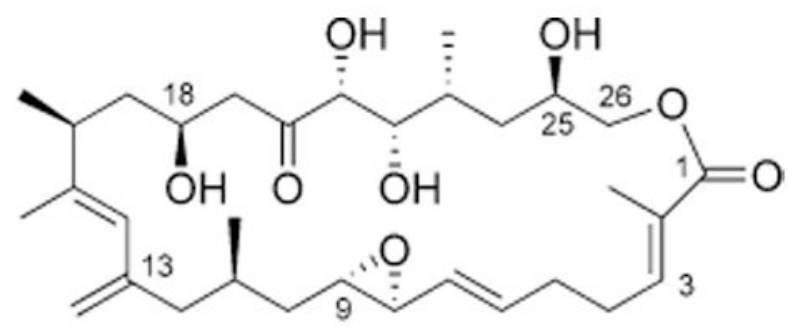

\section{amphidinolide $\mathrm{H}(2)$ :}



Figure 1.

Amphidinolides G (1) and H (2). 



Figure 2.

Retrosynthetic analysis of amphidinolide H (2). 
<smiles>[3H][C@@H](CC[OH+])C(C)=O</smiles>
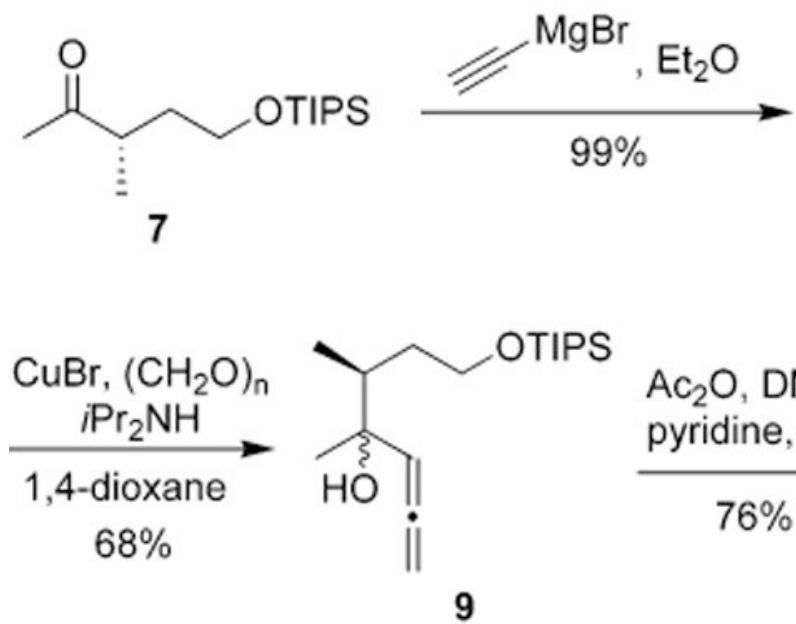

Scheme 1

Synthesis of Allenic Acetate $\mathbf{1 0}$
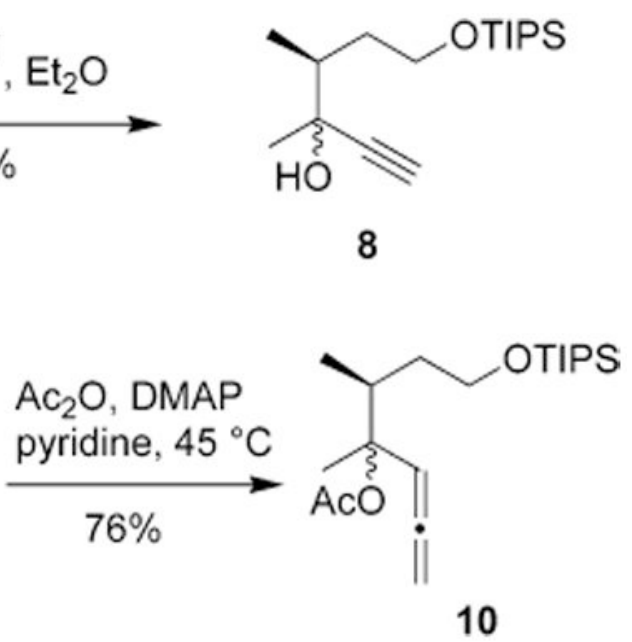

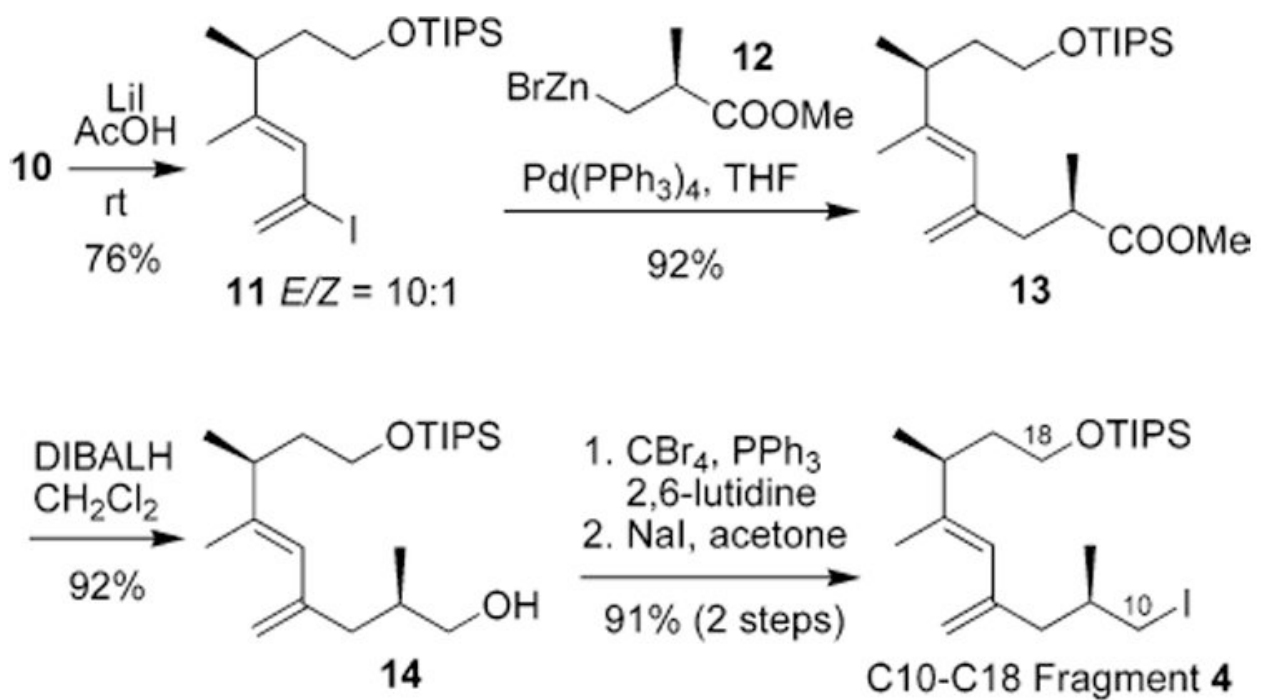

Scheme 2.

Synthesis of the C10-C18 Fragment 4 

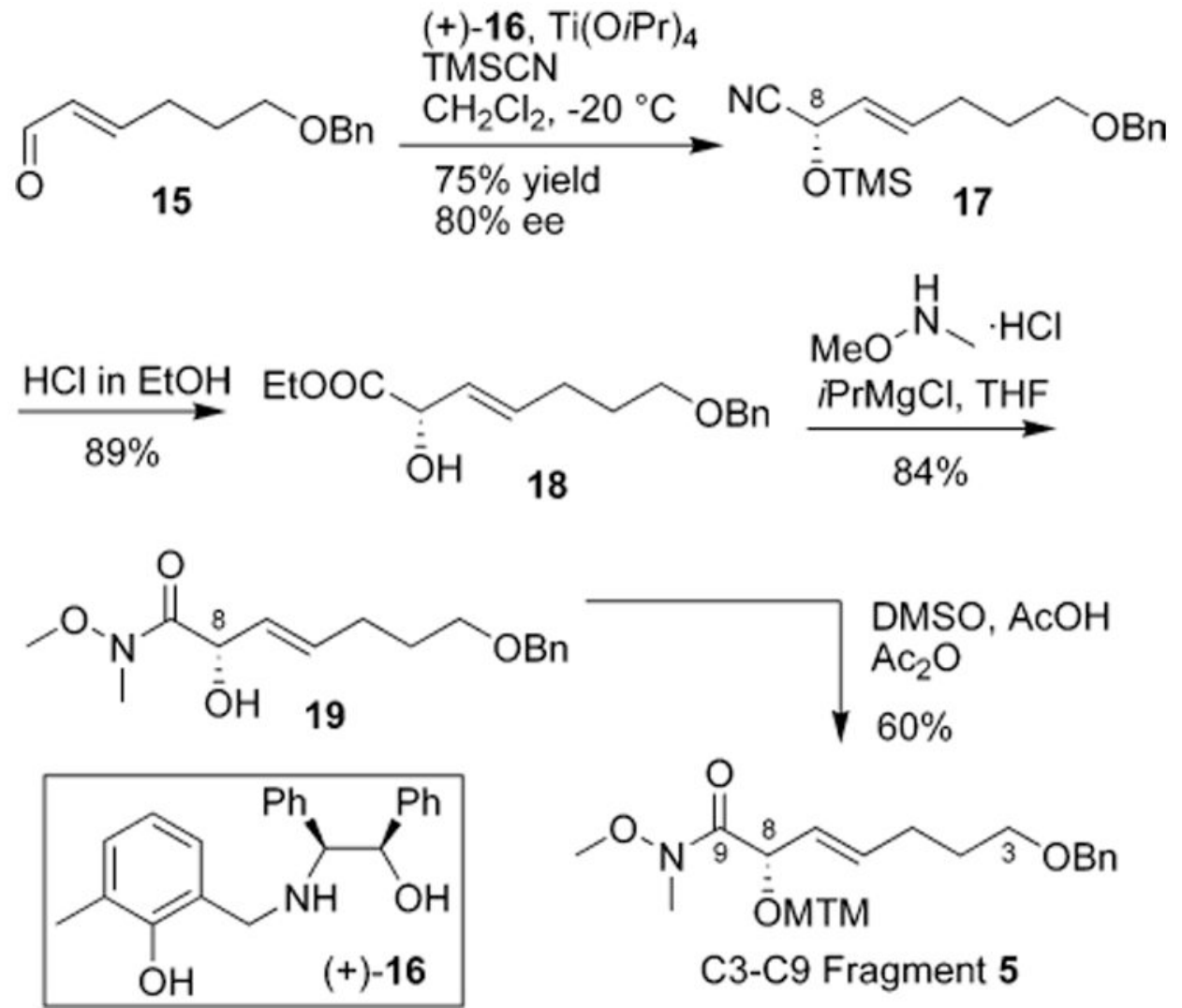

Scheme 3.

Synthesis of the C3-C9 Fragment 5 

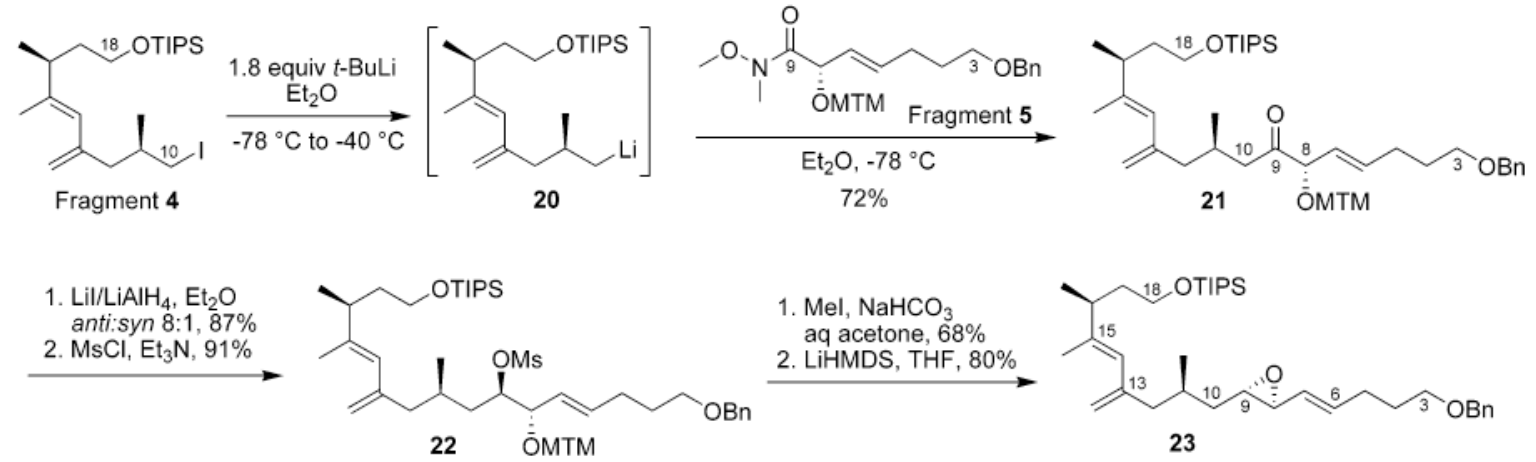

Scheme 4.

Coupling of Fragment 4 with Fragment 5 and Completion of the C3-C18 Subunit 23 